\title{
ANÁLISE DO SIGNIFICADO DAS ÁREAS PROTEGIDAS DE ITIRAPINA (SP) E SUA RELAÇÃO COM A COMUNIDADE URBANA DO ENTORNO COMO SUBSÍDIO ÀS AÇÕES DE EDUCAÇÃO AMBIENTAL
}

\author{
Fernando César Andreoli1 \\ Helena Dutra - Lutgens²
}

\begin{abstract}
RESUMO
As Estações Ecológica e Experimental de Itirapina, administradas pelo Instituto Florestal (IF), tem sua principal área de desenvolvimento para uso público, conhecida como Fazendinha, envolvida pela zona urbana do município de Itirapina. Embora o perímetro urbano não esteja incluído na zona de amortecimento da unidade, tal localização responde por uma variedade de impactos negativos e positivos entre a cidade e as áreas protegidas. Um exemplo disso foi a aparição de uma onça parda (Puma concolor) em 2010, no bairro Jardim Nova Itirapina, próximo a Estação Experimental. O presente trabalho analisouA partir do evento: aparecimento da onça parda, a perspectiva dos moradores desse bairro sobre o papel das unidades de Itirapina na manutenção da qualidade ambiental de seus ecossistemas e na conservação da biodiversidade no contexto local, visando definir estratégias de educação ambiental dirigidas a esses moradores, que contribuam efetivamente com a conservação das áreas protegidas. Utilizou-se a metodologia de Pesquisa Ação na criação de alternativas de educação ambiental, promoção do debate e fomento à participação popular. Os resultados mostraram que a população do entorno desconhece muitos aspectos legais, funcionais e ambientais relacionados às unidades de conservação, entretanto consegue observar e relatar as relações positivas e negativas entre as mesmas e os moradores do entorno. Há pouco interesse de participação dos moradores nessas questões, que mesmo acreditando na educação ambiental como instrumento para mudanças, pouco se veem como agentes desse processo.
\end{abstract}

Palavras - chave: Educação ambiental, Unidades de Conservação, Pesquisa Ação.

\section{ANAL YSIS OF THE MEANING OF PROTECTED AREAS ITIRAPINA (SP ) AND ITS RELATIONSHIP WITH THE COMMUNITY AS URBAN ENVIRONMENT ALLOWANCE TO ENVIRONMENTAL EDUCATION ACTIONS}

\begin{abstract}
The Ecological and Experimental Stations of Itirapina, managed by the Forest Institute (IF), have their main public development area, known as Fazendinha, surrounded by the urban zone of Itirapina city. Although the urban perimeter is not included in the buffer zone of the unity, this proximity is the cause of a variety of positive and negative impacts of the urban zone on the protected areas. One example of these impacts is the presence of a cougar (Puma concolor) in 2010, at the Jardim Nova Itirapina neighborhood, near the Experimental Station. In respect to this event, the present work has analyzed: the presence of the cougar, the perspective of the residents of this neighborhood on the role of Itirapina conservation unities on the maintenance of the environmental quality of the ecosystems and on the biodiversity conservation in the local context, aiming to define environmental educational strategies for residents, strategies that effectively contribute to the conservation of protected areas. The Research Action methodology was used to create alternative ways to promote environmental
\end{abstract}


da Alta Paulista

education, debate, and popular participation. Results showed that local residents ignore several legal, functional, and environmental aspects of the conservation unities. However, they observe and communicate positive and negative interactions between the unities and each unity and local residents. There is little interest in participating in these issues and, even though they believe that environmental education is a tool that can make a difference, only a few see themselves as agents in this process.

KEYWORDS: Environmental education, protected areas , Action Research.

\section{ANÁLISIS DEL SIGNIFICADO DE ÁREAS PROTEGIDAS ITIRAPINA ( SP ) Y SU RELACIÓN CON LA COMUNIDAD COMO MEDIO URBANO SUBSIDIO PARA ACCIONES DE EDUCACIÓN AMBIENTAL}

\begin{abstract}
RESUMEN
Las Estaciones Ecológicas y Experimental Itirapina, administrado por el Instituto Forestal (SI), tiene su área de desarrollo principal para el uso público, conocido como Fazendinha, rodeada de la zona urbana del municipio de Itirapina. Aunque el área urbana no está incluida en la zona de amortiguamiento unidad, una ubicación representa una variedad de impactos positivos y negativos entre la ciudad y las áreas protegidas. Un ejemplo de esto fue la aparición de un puma (Puma concolor) en 2010, en el barrio de Nueva Itirapina Jardín, cerca de la Estación Experimental. Esta trabajo a analizado mediante el evento: la aparición del puma, la perspectiva de los vecinos de este barrio en el papel de las unidades Itirapina en el mantenimiento de la calidad ambiental de los ecosistemas y la conservación de la biodiversidad en el contexto local, con el fin de definir estrategias de educación ambiental dirigidas estos residentes que contribuyan eficazmente a la conservación de las áreas protegidas. Se utilizó la metodología de investigación-acción en la creación de la educación ambiental alternativa, promover el debate y el fomento de la participación popular. Los resultados mostraron que la población circundante no tiene conocimiento de muchos aspectos legales, funcionales y ambientales relacionados con las áreas protegidas, sin embargo se puede observar y reportar las relaciones positivas y negativas entre ellos y los residentes de los alrededores. Hay poco interés en la participación de los residentes en estos asuntos, aunque acreditando en la educación ambiental como herramienta para el cambio, pocos ven a sí mismos como agentes de este proceso.

Palabras Clave: educación ambiental , áreas protegidas , la investigación-acción
\end{abstract}




\section{1- INTRODUÇÃO}

O intenso processo de urbanização que a civilização moderna apresenta no período pós- revolução industrial, aliado a um modelo de desenvolvimento calcado na máxima exploração de recursos naturais em tempo mínimo, levou a perda de ambientes naturais preciosos para a vida.

\footnotetext{
"A urbanização se caracteriza pela substituição dos ecossistemas naturais por centros de grande densidade criados pelo homem, em que a espécie dominante é a humana e o meio está organizado para permitir a sua sobrevivência" (NUCCI \&PRESOTTO, 2009).
}

Em contra partida, as unidades e conservação representam uma estratégia fundamental para a conservação da biodiversidade. Em meio a um processo de desenvolvimento caótico, esses remanescentes naturais da paisagem constituem-se na principal, e em muitos casos, na única esperança de sobrevivência para muitas espécies (DUTRA - LUTGENS, 2010), além de serem fundamentais para a manutenção dos serviços ecossistêmicos. Assim, pode ser observada uma relação bastante dicotômica entre assentamentos urbanos e áreas protegidas, já que ao mesmo tempo em que as populações humanas buscam usufruir dos bens e serviços dos ecossistemas contidos nas unidades de conservação, continuam a alterar o ambiente de seu entorno causando impactos negativos sobre a mesma.

Wittemyer et al. (2008), calcularam as taxas médias de crescimento populacionais nas áreas de entorno de 306 unidades de conservação da África e da América Latina entre 1960 e 2000, utilizando como parâmetro dimensional de área o raio de $10 \mathrm{Km}$ a partir dos limites das Unidades. Os autores observaram que o crescimento populacional humano no entorno das áreas protegidas foi significativamente superior às taxas observadas em eco rregiões correspondentes, sugerindo que unidades de conservação atraem assentamentos humanos.

O simples estabelecimento de uma Unidade de Conservação não constitui garantia para a conservação de seus recursos naturais, o conteúdo da reserva estará influenciado determinantemente pelo conjunto ao qual ela pertence (SHAFER, 1992).No sentido de manter a qualidade ambiental das áreas protegidas e manter relações equilibradas com o entorno, de forma a permitir à comunidade 
usufruir dos benefícios de viver próxima à uma unidade de conservação e ao mesmo tempo garantir a perpetuação dos recursos naturais e o desenvolvimento do conhecimento a cerca dos mesmos, além das normas e restrições específicas inerentes ao conceito de zonas de amortecimento, é de suma importância a existência de um programa educação ambiental.

Segundo Santos et al. (2009), as unidades de conservação são "externas" ao "território cotidiano" da maioria das pessoas, o que as torna instrumentos adequados para a preparação dos atores sociais que agem nas relações entre a unidade de conservação e a sua zona de amortecimento buscando a solução dos problemas socioambientais. De acordo com a Política Nacional de Educação Ambiental (BRASIL, 1999) o enfoque democrático e participativo é um dos princípios básicos para a educação ambiental.

No município de Itirapina, Estado de São Paulo, localizam-se a Estação Experimental e a Estação Ecológica de Itirapina, administradas pelo Instituto Florestal (IF), com uma área de cerca de 5.500 ha, que desenvolvem juntas, um leque de atividades que abrange desde a conservação de recursos naturais à produção florestal, passando por pesquisa científica, uso público, recuperação de áreas alteradas, etc. (DELGADO et al., 2004).

A zona urbana do município de Itirapina faz divisa com a Estação Experimental, mais especificamente com a área denominada "Fazendinha". Tal localização responde por uma variedade de impactos negativos e positivos entre a unidade de conservação e a ocupação do entorno(DUTRA-LUTGENS, 2000).

No dia 13 de setembro de 2010, uma onça parda, Puma comcolor, foi avistada na copa de uma árvore no bairro Nova Itirapina, periferia do município. Após várias tentativas de resgate, o animal foi capturado, examinado por veterinários e reintroduzido na unidade de conservação.

O aparecimento da onça parda e suas consequências no "território cotidiano" da população podem servir como indicador das relações entre comunidade e unidade de conservação incentivando o debate popular sobre as questões ambientais em geral.

Diante do exposto, cabem os seguintes questionamentos: Qual é o papel das áreas protegidas, na perspectiva dos moradores da zona urbana? Que importância, esses mesmos moradores, atribuem à conservação da biodiversidade? 
Quais são as relações entre as áreas protegidas e a comunidade do entorno? Como a educação ambiental pode contribuir na evolução dessas relações?

\section{2- OBJETIVO}

A partir do evento: aparecimento da onça parda, analisar o significado das Estações Ecológica e Experimental de Itirapina e de sua zona de amortecimento para a manutenção da qualidade ambiental de seus ecossistemas e para conservação da biodiversidade no contexto local, sob a perspectiva dos moradores do bairro Nova Itirapina, visando definir estratégias de educação ambiental dirigidas a esses moradores, que contribuam efetivamente com a conservação das áreas protegidas.

\section{3- METODOLOGIA}

O presente trabalho utilizou como referencial teórico-metodológico a Pesquisa Ação por ser esta uma metodologia que permite que a pesquisa desenvolva-se em estreita associação com uma ação ou com a solução de umproblema coletivo, além disso, pesquisador e participantes estão envolvidos de modo cooperativo ou participativo (THIOLLENT, 1994).

A pesquisa foi realizada em duas etapas, na primeira foram realizadas as entrevistas com os moradores do bairro Jardim Nova Itirapina e a segunda consistiu na realização de encontros de planejamento com os mesmos. De acordo com Tozoni-Reis (2005), a metodologia de Pesquisa Ação em Educação Ambiental está centrada em três "práticas" articuladas: a produção de conhecimento, ação educativa e a participação dos envolvidos. A opção pela técnica de coleta de dados através de entrevista foi feita para se valer de respostas mais profundas para que os resultados fossem atingidos de forma fidedigna. Segundo Rosa \& Arnoldi (2008) só os sujeitos selecionados e conhecedores do tema em questão serão capazes de emitir opiniões concretas a respeito do assunto.

As entrevistas com os moradores do bairro Nova Itirapina seguiram um roteiro contendo questões fechadas (múltipla escolha) e abertas para a viabilidade das análises das entrevistas de forma quantitativa e qualitativa. A execução das entrevistas deu-se em visitas ao bairro onde foram abordando moradores de diversas idades. O sistema de amostragem escolhido foi o do tipo bola-de-neve 
(ZAMBERLAN, 2008), no qual a primeira abordagem é aleatória e na sequência solicita-se ao indivíduo entrevistado que indique outras pessoas que ele julga poderem contribuir com a pesquisa.

O tempo médio das entrevistas foi de aproximadamente 20 minutos, buscando evitar ultrapassar 50 minutos, conforme recomendação de Rosa e Arnoldi (2008).

Apresentamos a seguir o roteiro de entrevista utilizado:

\section{Roteiro de entrevistas}

Data:

Nome:

Idade : Ocupação:

1. Há quanto tempo mora na cidade? Quanto tempo nesse bairro?

2. Conhece as áreas conservadas (preservadas) na região? Quais? Como as identifica?

3. Conhece a Estação Experimental de Itirapina (Fazendinha)? Se sim, com que frequência à visita? (quantas vezes por mês/ano)

4. Quais dessas atividades você acha que são permitidas lá:

\subsection{Pescar}

\subsection{Caçar}

\subsection{Nadar}

\subsection{Entrar numa trilha}

4.5.Andar com o cachorro

4.6. Matar cobra se achar:

5. Conhece a Estação Ecológica? Se sim, ela é diferente da Experimental? Por quê?

6. A existência dessas áreas pode te trazer algum benefício? Quais?

7. A existência dessas áreas pode te trazer algum problema? Quais?

8. Ficou sabendo da onça encontrada no bairro?

9. Sabe de onde ela veio e por qual motivo?

10. Você acha que ela pode um dia voltar? Mudou alguma coisa no bairro depois desse acontecimento?

11. Já observou outros bichos na área urbana? Quais? Acha isso normal?

12. Se, um dia, as Unidades de Conservação acabar, se tudo for desmatado, o que acha que vai mudar neste bairro? 
13. Se, um dia, a "Fazendinha" for totalmente abandonada e ninguém mais entrar lá, o que acha que pode acontecer?

14. O que acha que é preciso fazer para resolver o problema do desmatamento, caça e invasão de animais?

14.1- Muro14.2- Multa14.3- Sensibilização14.4- Transformar num lugar de lazer

15. Você acha que pode melhorar e relação entre a cidade e as áreas protegidas se existir a educação ambiental, junto com o diálogo e a participação da comunidade na construção de propostas?

16. Estamos formando um grupo de pessoas interessadas em melhorar essa relação do bairro com a unidade de conservação. Dispostas a aprender, a trocar experiências e a construir um projeto de educação ambiental para o bairro. Gostaria de participar conosco?

17. Se sim, quais os melhores dias, locais e horários você poderia participar?

Foram realizados dois encontros de planejamento, o primeiro teve enfoque sobre os conceitos e percepções a respeito das unidades de conservação e das relações das mesmas com o entorno e o segundo enfocou a criação de estratégias de educação ambiental com a comunidade tendo em vista a melhoria das relações com as áreas protegidas.

\section{4- RESULTADOS}

\subsection{Análise qualitativa das entrevistas}

Os entrevistados reconhecem as áreas conservadas na região e as identificam com os seguintes nomes, classificados na Tabela 1:

Tabela 1- Áreas protegida identificadas pelos entrevistados.

\section{Identificações citadas}

Área

Fazendinha, Córrego do Limoeiro, Lagoa do Cobreiro, Porto e Horto 1 Florestal.

Morro do Baú, Broa e distrito de Itaqueri da Serra.

2

Córrego do Mariazinha, Rio Passa Cinco, Ubá, Ilha do Morcego, 3

Cachoeira do Saltão, Morro Pelado e Pesque \& Pague. 
Agrupou-se como: Área 1 as identificações de áreas pertencentes as unidades de Itirapina; Área 2,identificações localizadas na zona de amortecimento das unidades de Itirapina; Área 3, as identificações das áreas externas as unidades e também externas à zona de amortecimento.

Observa-se que ninguém citou o nome oficial da Estação Experimental sendo sempre identificada como a Fazendinha. Também é possível observar que os entrevistados fizeram associação entre áreas conservadas e áreas turísticas.

A respeito dos benefícios proporcionados pelas unidades de conservação de Itirapina, a maioria dos entrevistados identificou a qualidade do ar. Em segundo lugar, citaram os benefícios advindos do uso sustentável da unidade, como emprego e renda. O Projeto "Flor da Idade, Flor da Cidade", um projeto socioambiental desenvolvido na Estação Experimental, também foi lembrado.

Outros benefícios citados foram: utilização como área de lazer, turismo, diversidade de animais, equilíbrio do sistema e qualidade de vida.

Quando perguntadas se essas áreas podem trazer algum prejuízo ou algum problema todos responderam que não.

Perguntados sobre o que poderia ter levado a onça até o bairro em questão, as principais respostas foram: desmatamento, queimadas e a invasão humana no habitat natural do animal. A maioria não soube responder de onde veio a onça, alguns acreditam que o animal não veio da "Fazendinha", pois nunca souberam da existência desse animal no local. Vale observar que segundo o Plano de Manejo Integrado das Estações Ecológica e Experimental de Itirapina (ZANCHETTA et al., 2006) existem registros da espécie Puma concolorem ambas as unidades.

A respeito das possíveis soluções para melhorar e relação das unidades de conservação com a comunidade do entorno foram sugeridas quatro alternativas, as quais os entrevistados teceram as seguintes opiniões:

a- Cercar as unidades com um muro, isolando-as da cidade para evitar problemas de caça, desmatamento e invasão de animais: Todos responderam serem completamente contra esse tipo de solução, pois acabaria com o contato da comunidade com a natureza.

b- Aplicação de multas e leis mais enérgicas: No geral concordam com essa alternativa, desde que seja acompanhada de outras soluções. 
c- Educação ambiental, sensibilização e informação aos visitantes e a população: Todos responderam a favor dessa solução.

d- Aumentar e incentivar os espaços de lazer e recreação: No geral concordam com essa alternativa desde que sejam promovidas ações para a existência de um turismo menos impactante que proporcione além de lazer e recreação o contato com a natureza e a reflexão.

\subsection{Análise quantitativa das entrevistas}

Quando indagados sobre o tempo em que vivem no bairro, obteve-se os seguintes dados: Cerca de 50\% dos entrevistados residem no bairro entre 10 e 20 anos, $20 \%$ há menos de 10 anos e $30 \%$ há mais de 20 anos. Esses dados reforçam ser esse um bairro de urbanização recente, acelerada nas últimas décadas, visto que quase metade dos entrevistados passou a viver no Jardim Nova Itirapina entre dez a vinte anos.

Com relação ao conhecimento da Estação Experimental, 89\% dos entrevistados responderam que a conhecem, mais precisamente a área chamada de Fazendinha, e já a visitaram alguma vez. Perguntados sobre a frequência com que visitam a unidade de conservação, muitos responderam que visitavam frequentemente no passado e que ultimamente não visitam mais.

Sobre o conhecimento dos moradores a respeito das atividades públicas realizados na Estação Experimental, obteve-se as respostas apresentadas na Tabele 2.

Tabela 2- Atividades que os entrevistados realizam na Estação Experimental

\begin{tabular}{llll}
\hline Atividade: & Permitido & Proibido & Não sabe \\
\hline Pescar & $68,2 \%$ & $27,3 \%$ & $4,5 \%$ \\
Caçar & 0 & $100 \%$ & 0 \\
Nadar & $6,8 \%$ & $90,9 \%$ & $2,3 \%$ \\
Entrar numa trilha & $29,5 \%$ & $50 \%$ & $20,5 \%$ \\
Andar com cachorro & $56,8 \%$ & $36,4 \%$ & $6,8 \%$ \\
Matar cobra se achar & $11,4 \%$ & $79,5 \%$ & $9,1 \%$ \\
\hline
\end{tabular}


Esses dados nos permitem inferir que o conhecimento dos entrevistados sobre as unidades de Itirapina é bastante insipiente, por exemplo, sobre a Estação Ecológica, $79 \%$ dos entrevistados nunca ouviram falar dessa unidade de conservação, 14\% sabem da existência da mesma, porém não sabem o que a diferencia da Estação Experimental e apenas 7\% dos entrevistados conhece a existência e sabe diferenciar uma área da outra.

Sobre a aparição da onça, $84 \%$ responderam que a viram, indicando a grande repercussão desse evento na época. Porém $86 \%$ disseram que nada mudou na rotina do bairro após o surgimento do animal, indicando a possibilidade desse acontecimento ter se tornado apenas um caso isolado sem ter provocado muita reflexão.

Por último, quando perguntados se participariam das reuniões de planejamento correspondentes a segunda etapa desta pesquisa $79 \%$ dos entrevistados responderam que sim, e que também convidariam seus vizinhos e amigos do bairro para participarem. Assim, anotou-se o contato dessas pessoas para poder convidá-las nessa próxima etapa.

\subsection{Propostas resultantes das oficinas de planejamento.}

Com base nos resultados obtidos nas entrevistas, nas oficinas de planejamento e também observando as diretrizes do ProNEA (BRASIL, 2005), foi possível construir as seguintes estratégias para o projeto de educação ambiental:

\section{0 que queremos? (objetivos)}

- Melhorar a relação da Comunidade com as Áreas Protegidas;

- Preservar a natureza mantendo a qualidade do ar, água e a diversidade das espécies;

- Melhorar a qualidade de vida da população;

- Criar a visão da população como agente transformador, compreendendo a importância do diálogo e da participação;

- Mudança de valores, visando uma mudança de atitudes para a sustentabilidade e que sejam também compatíveis com valores histórico-culturais enraizados na comunidade. 
da Alta Paulista

\section{Que resultados esperamos? (indicadores de acompanhamento)}

-Aumento da frequência de visitação na Estação Experimental;

- Redução da caça, vandalismo e demais atividades ilegais dentro das unidades;

- Aumento da participação da população nas tomadas de decisões (reuniões sobre o Plano de Manejo, comitês locais, etc.);

- Mais pessoas denunciando os casos de caça, desmatamento ilegal, entre outros;

- Aumento de moradores auxiliando na educação ambiental como multiplicadores;

- Boas práticas individuais locais como o plantio de árvores e redução do consumo de água e energia;

- Boas práticas coletivas locais como a criação de grupos ambientalistas no bairro; -Boas práticas com visão global como a redução, reutilização e reciclagem de resíduos;

-Reflexões sobre o padrão de consumo e a utilização de produtos e serviços menos poluidores.

\section{Que ações podem ser feitas? (metas)}

- Divulgação da importância das unidades de conservação, das suas atividades e dos seus benefícios;

- Instruir a população sobre o que fazer quando surgirem animais silvestres na cidade;

- Aumentar a fiscalização contra caça, vandalismo e demais atividades ilegais dentro das unidades;

- Introdução de mais placas de sinalização, informação e demais meios para instrução correta dos usos públicos da Estação Experimental;

- Introdução de mais monitores e visitas monitoradas de educação ambiental nas unidades;

- Melhorar a infraestrutura para a visitação na Estação Experimental (sanitários, iluminação, etc.);

- Atividades de Educação Ambiental nas escolas;

- Eventos de Educação Ambiental constantes e integrados com a realidade bairro;

- Intervenções no bairro, como no córrego Mariazinha;

- Espaços de participação e debate de temas ambientais onde a população possa opinar a vontade;

- Diálogo técnico x comunidade $x$ administração, focando na compreensão; 
- Integrar o perímetro urbano na zona amortecimento das unidades;

- Integrar a Estação Experimental no Plano Diretor Municipal;

- Observar as diretrizes de educação ambiental presentes nos planos do Comitê de bacia hidrográfica da UGRHI Tietê/Jacaré e da APA Corumbataí onde as unidades e o município se encontram.

\section{5- CONCLUSÃO}

Observando a grande proporção de participantes que desconheciam a existência da Estação Ecológica e as incertezas dos moradores sobre os usos pertinentes à Estação Experimental é possível concluir que a comunidade residente no bairro Nova Itirapina não conhece as questões legais e ambientais ligadas às Estações Ecológica e Experimental de Itirapina e sua zona de amortecimento. Não obstante, demonstraram conhecer os benefícios proporcionados pelas unidades de conservação, como a melhor qualidade do ar, o lazer e o emprego. Também observam os conflitos como o atropelamento de animais na rodovia próxima e o lançamento de esgoto da rua Bororós na represa da Estação Experimental. Tais declarações comprovam a hipótese de que a população percebe impactos positivos e negativos gerados da relação entre a zona urbana do município e as áreas protegidas ainda que desconheçam os nomes oficias das áreas protegidas e a legislação pertinente à elas.

A população residente no bairro Nova Itirapina acredita na educação ambiental como trajetória para melhorar as relações entre a comunidade e as áreas protegidas, ainda que não se reconheça como agente transformador desse processo. Dessa forma a baixa participação da comunidade amplia as dificuldades, pois o enfoque democrático e participativo é um dos princípios básicos da educação ambiental. Desta forma, as estratégias de educação ambiental apresentadas pela pesquisa foram fundamentadas na realidade socioambiental da comunidade do Jardim Nova Itirapina, pode-se afirmar que tais propostas estão à disposição para servir como subsídios de planos, programas ou projetos de educação ambiental, dirigidos aos moradores do referido bairro, que contribuam efetivamente com a conservação das áreas protegidas. 


\section{6- REFERÊNCIAS BIBLIOGRÁFICAS}

BRASIL. Lei no 9795, de 27 de Abril de 1999. Dispõe sobre a educação ambiental, institui a Política Nacional de Educação Ambiental e dá outras providências. Disponível em:< http://www.planalto.gov.br/ccivil_03/leis/19795.htm>. Acesso em :25 de jul. 2013.

BRASIL. Ministério do Meio Ambiente, Diretoria de Educação Ambiental; Ministério da Educação. Coordenação Geral de Educação Ambiental. Programa nacional de educação ambiental ProNEA. 3. Ed. Brasília : Ministério do Meio Ambiente, 2005.

DELGADO,J.M.;BARBOSA,A.F.;SILVA,C.E.da;SILVA,D.A.;ZANCHETA,D.;GIANOTTI,E.; PINHEIRO,G.de S.; DUTRA-LUTGENS,H.; FACHIN, H.C.; MOTA,I.S. da; LOBO,M.; NEGREIROS,O.C.; ANDRADE,W.J. Plano de manejo integrado das

Unidades de Conservação de Itirapina-SP. São Paulo: Instituto Florestal, 2004. 171p.

DUTRA - LUTGENS, H. Caracterização ambiental e subsídios para o manejo da zona de amortecimento da Estação Experimental e Ecológica de Itirapina-SP. 2000. Dissertação (Mestrado em Ecologia) - Universidade Estadual Paulista, Rio Claro, 2000.

DUTRA-LUTGENS, H. Metodologia participativa aplicada ao manejo da zona de amortecimento das Estações Ecológica e Experimental de Itirapina, SP. 2010. Tese (Doutorado em Ecologia) Universidade federal de São Carlos, São Carlos, 2010.

ROSA,M.V.F.P.C;ARNOLDI,M.A.G.C. A entrevista na pesquisa qualitativa: mecanismo para validação dos resultados. Belo Horizonte: Autêntica, 2008.

SANTOS,J.E.; SATO,M.; ZANIN,E.M.; MOSCHINI,L.E. O Cenário da Pesquisa no diálogo Ecológico-Educativo. São Carlos: SPRiMa, 126p. 2009.

THIOLLENT, M. Metodologia da Pesquisa-Ação nas Organizações. 6ª edição. São Paulo: Cortez, 1994.

TOZONI-REIS, M. F. C. Pesquisa-ação: compartilhando saberes. Pesquisa e ação educativa ambiental. In: FERRARO JR., L.A. (Org.). Encontros e caminhos: formação de educadoras (es) ambientais e coletivo educadores. Brasília: Ministério do Meio Ambiente, 2005.

ZAMBERLAN, L. Pesquisa de mercado. Ijuí: Ed. Unijuí, 2008.

ZANCHETTA, D. et al. Plano de manejo integrado: Estações ecológica e experimental de ItirapinaSP.1ำ revisão.SãoPaulo:Instituto Florestal, 2006. 